\title{
Características de Carcaça de Cordeiros Suffolk Abatidos em Diferentes Idades ${ }^{1}$
}

\author{
Mauro Sartori Bueno², Eduardo Antonio da Cunha ${ }^{3}$, Luiz Eduardo dos Santos ${ }^{2}$, \\ Domingos Sanchez Roda ${ }^{3}$, Frederico Fontoura Leinz ${ }^{4}$
}

RESUMO - Foram avaliadas as proporções dos componentes não-carcaça e as características de carcaça de 35 cordeiros Suffolk, abatidos com idades médias de 90, 130 ou 170 dias, alimentados com silagem de milho e ração concentrada (19,6\% de PB). O aumento da idade de abate acarretou incremento linear dos pesos de abate e de carcaça e diminuição linear na proporção de alguns componentes não-carcaça, como sangue, cabeça, patas e vísceras cheias, o que resultou em aumento linear do rendimento de carcaça. As proporções dos componentes da carcaça foram alteradas pelo aumento da idade de abate, observando-se aumento linear na porcentagem de gordura, diminuição linear na de ossos e nenhuma alteração na de músculos. Os cortes efetuados nas carcaças mostraram diminuição linear da porcentagem de traseiro, nenhuma alteração na de dianteiro e aumento linear na de costilhar, com o aumento da idade de abate. As medidas de carcaça e compacidade mostraram aumento linear com o aumento da idade de abate. A idade de abate de cordeiros Suffolk criados intensivamente para produzir carcaças adequadas ao mercado consumidor da região Centro-Sul do Brasil fica entre 110 e 130 dias de idade.

Palavras-chave: gordura, músculo, osso, ovinos, rendimento

\section{Carcass Characteristics of Suffolk Lambs Slaughtered at Different Ages}

\begin{abstract}
The effect of slaughter age on non-carcass components and carcass characteristics was evaluated in 35 Suffolk lambs slaughtered at average age of 90, 130 or 170 days, fed corn silage and concentrate (19.6\% CP). As the slaughter age increased, animal live weight and carcass weight linearly increased, and some non-carcass components as blood, head, legs and full viscera percentage linearly decreased, leading to a linear increase in carcass yield. As the slaughter age increase, it was observed change in the proportion of carcass components with a linear increase of fat percentage, a linear decrease in bones percentage and no change in the muscle percentage. A linear decrease in the hindquarter, a linear increase in the ribs and no change in the forequarter carcass cuts was observed with increasing slaughter age. Higher slaughter age led to a linear increase in carcass measures and compactness. The slaughter age of Suffolk lambs, to produce suitable carcasses for retail, is between 110 and 130 days of age.
\end{abstract}

Key Words: bone, dressing, fat, muscle, sheep

\section{Introdução}

A ovinocultura na região Centro-Sul do pais, a qual tem crescido progressivamente nos últimos anos, visa a produção de cordeiros para abate. O sistema intensivo de acabamento de cordeiros em confinamento, baseado em dietas com elevada concentração energética, mostra-se adequado, pois diminui o tempo necessário para os animais atingirem o peso de abate e minimiza os problemas sanitários.

A padronização das carcaças de cordeiros a serem colocadas no mercado é necessária para valorizar o produto e atrair o consumidor. As carcaças devem apresentar elevada porcentagem de múscu- los, cobertura de gordura subcutânea uniforme e teor de gordura adequado ao mercado consumidor, características definidas pelo grau de maturidade do genótipo. TAYLOR (1985) mostra que o aumento da maturidade dos animais leva a aumento na proporção de gordura, diminuição na de ossos e pouca mudança na de músculos.

O consumidor tem preferência por carcaças de tamanho moderado entre $12-14 \mathrm{~kg}$, o que determina o abate dos animais entre $28-30 \mathrm{~kg}$ de peso vivo (SIQUEIRA, 1999). Cordeiros provenientes de animais de genótipos com peso adulto elevado apresentam-se menos maduros em determinado peso, quando comparados com animais de genótipos com menor

\footnotetext{
1 Parcialmente financiado pela FAPESP $(95 / 04020-6)$

2 Pesquisador Científico, Instituto de Zootecnia - Centro de Nutrição e Alimentação Animal, CP 60, CEP 13460-000, Nova Odessa-SP Fone: (0xx19)466-9400. E.mail: msbueno@izsp.br

3 Pesquisador Científico, Instituto de Zootecnia - Centro de Etologia, Ambiência e Manejo. E.mail: ceam@izsp.br

4 Pesquisador Científico, Instituto de Zootecnia - Núcleo de Pesquisa Zootécnica do Sudoeste, Itapetininga, SP.
} 
peso adulto. Dessa maneira, o peso ideal de abate deve levar em consideração as características desejáveis da carcaça como: porcentagem de ossos, gordura e músculos, cobertura de gordura, entre outros, para cada raça, visando atender às exigências do mercado consumidor.

A raça Suffolk, entre as especializadas para corte, é uma das mais exploradas no Estado de São Paulo para produção de cordeiros puros ou mestiços para abate, fazendo-se necessário o conhecimento das características de carcaças de animais desta raça em sistema de produção intensivo.

A composição das carcaças pode ser estimada por meio da mensuração da espessura da gordura subcutânea tomada acima do músculo longissimus dorsi na altura da inserção da $12-13^{\text {a }}$ costela, pois apresenta boa correlação com o seu teor de gordura (WOOD e MACFIE, 1980; FISHER, 1990). A cobertura de gordura da carcaça quantificada visualmente numa escala de zero a cinco também pode ser usada para estimar o teor de gordura na carcaça (FISHER, 1990), sendo um método rápido, prático e barato.

As medidas de carcaça servem para caracterizar o produto, apresentam alta correlação com seu peso e podem ser utilizadas como indicadoras de características de carcaça (WOOD et al., 1980; EL KARIM et al., 1988).

A compacidade das carcaças mostra a relação entre o seu peso e o comprimento das carcaças, servindo para avaliação da quantidade de tecido depositado por unidade de comprimento (SANTOS et al., 1998).

A queda do $\mathrm{pH}$ das carcaças para valores abaixo de 6,0 (LEMOS NETO et al., 1998), que caracteriza o processo normal de transformação dos músculos em carne, é necessária para tornar o produto adequado ao paladar humano. Vários fatores podem determinar a queda eficiente no $\mathrm{pH}$, dentre esses destacam-se a alimentação, a raça e a idade do animal.
O objetivo deste estudo foi avaliar as proporções dos componentes-não-carcaça e as características de carcaça de cordeiros Suffolk criados intensivamente, visando determinar a idade ideal de abate para a obtenção de carcaças com as melhores características para o mercado consumidor.

\section{Material e Métodos}

Cordeiros inteiros da raça Suffolk $(n=35)$ desmamados aos 60 dias de idade, com peso vivo médio de $14,6 \pm 1,2 \mathrm{~kg}$, foram confinados em baias coletivas com piso ripado suspenso na Unidade de Ovinos do Instituto de Zootecnia em Nova Odessa-SP. Foram alimentados com silagem de milho à vontade e ração concentrada (Tabela 1) na quantidade de 3,5\% do peso vivo, ajustada a cada 14 dias. Os animais foram abatidos seqüencialmente quando atingiram ao redor de 90,130 ou 170 dias de idade.

$\mathrm{O}$ abate foi realizado após jejum alimentar de 24 horas e foram pesados o sangue, as patas, o couro e a cabeça. Amarraram-se o esôfago e o reto e pesaram-se as vísceras cheias. O conjunto pulmãotraquéia-coração, o sistema digestivo (SD) cheio e o fígado foram separados e pesados. A gordura circundante do sistema digestivo foi separada e pesada, sendo denominada gordura mesentérica. Os rins foram retirados das carcaças quentes, juntamente com a sua gordura circundante, separados e pesados e a gordura foi denominada de perirenal. O SD cheio foi esvaziado e o peso do SD vazio e das vísceras vazias, determinado. Pesaram-se as carcaças e, em seguida, mediu-se o pH15 minutos após o abate $(\mathrm{pH} 0)$, por meio de pHmetro com eletrodo de penetração, em três locais: perna, lombo e paleta, calculando-se o valor médio.

As carcaças foram armazenadas a temperatura de $3{ }^{\circ} \mathrm{C}$ por 48 horas e pesadas novamente para determinação do rendimento de carcaça fria ou comercial. Nessa ocasião, mediu-se o pH novamente (pH48) como descrito anteriormente. Calculou-se a

Tabela 1 - Composição bromatológica dos alimentos utilizados para os cordeiros confinados Table 1 - Chemical composition of the feeds used in the feedlot lambs

\begin{tabular}{|c|c|c|c|c|c|c|}
\hline $\begin{array}{l}\text { Alimentos } \\
\text { Feeds }\end{array}$ & $\begin{array}{l}\mathrm{MS}(\%) \\
D M(\%)\end{array}$ & $\begin{array}{r}\mathrm{PB}^{1} \\
C P\end{array}$ & $\begin{array}{r}\mathrm{FB}^{1} \\
C F\end{array}$ & $\begin{array}{c}\mathrm{MO}^{1} \\
O M\end{array}$ & $\mathrm{Ca}^{1}$ & $\mathrm{P}^{1}$ \\
\hline $\begin{array}{l}\text { Silagem de milho } \\
\text { Corn silage }\end{array}$ & 29,5 & 7,5 & 27,9 & 95,2 & 0,19 & 0,16 \\
\hline $\begin{array}{l}\text { Ração concentrada } \\
\text { Concentrate diet }\end{array}$ & 86,3 & 19,6 & 7,5 & 93,1 & 0,76 & 0,62 \\
\hline
\end{tabular}


perda por oreio: \% perda de peso da carcaça fria em relação à carcaça quente. Subtraiu-se o peso do conteúdo gastrintestinal do peso ao abate dos animais e determinou-se o seu peso vazio e o rendimento verdadeiro. A área do músculo Longissimus dorsi (olho de lombo) e a espessura da gordura subcutânea foram medidas no corte realizado entre a $12^{\underline{a}}$ e $13^{\underline{a}}$ costelas. Atribuiu-se nota de zero (fraca) a cinco (excessiva) para a cobertura de gordura subcutânea das carcaças e mediu-se a largura da garupa (distância máxima entre os trocânteres de ambos os fêmures).

As carcaças foram cortadas ao meio e, na meiacarcaça esquerda, mensuraram-se o comprimento interno (da sínfese ísquio-pubiana até a primeira coste1a), a profundidade do tórax (largura máxima do tórax, entre as extremidades distais dos processos espinhosos da terceira e quarta vértebras torácicas e a inserção da terceira e quarta costelas no esterno, medido externamente), o comprimento da perna (distância entre o trocanter maior do fêmur até a junção tarso-metatarsal) e a circunferência da perna (perímetro da perna em sua largura máxima). A meiacarcaça esquerda foi pesada e separada em dianteiro (pescoço, membro anterior e cinco costelas), traseiro (perna, garupa, lombo separado do dianteiro entre a quinta e sexta costelas) e costilhar (costela, a partir da sexta, separadas do traseiro a uma distância de, aproximadamente, $2 \mathrm{~cm}$ da coluna vertebral, mais os músculos abdominais). Nesses cortes efetuou-se a separação física de seus componentes em ossos, gordura e músculos, os quais foram pesados e expressos como porcentagem dos cortes ou da meia-carcaça.

Foi utilizado um delineamento inteiramente ao acaso e as variáveis avaliadas foram submetidas à análise da variância e regressão polinomial com a idade de abate. Foram efetuadas correlações entre algumas variáveis.

\section{Resultados e Discussão}

Constam da Tabela 2 o peso ao abate e peso vazio dos animais, os componentes não-carcaça e as equações lineares que descrevem a relação entre a idade de abate em dias com essas variáveis. O peso ao abate (Figura 1) e o peso vivo vazio elevaram-se linearmente com o aumento da idade de abate, mostrando que os animais apresentaram crescimento contínuo durante o período, com média de ganho diário em peso de $252 \mathrm{~g}$ no período total de confinamento. O ganho de peso diário pode ser considerado adequado para animais de raça de corte

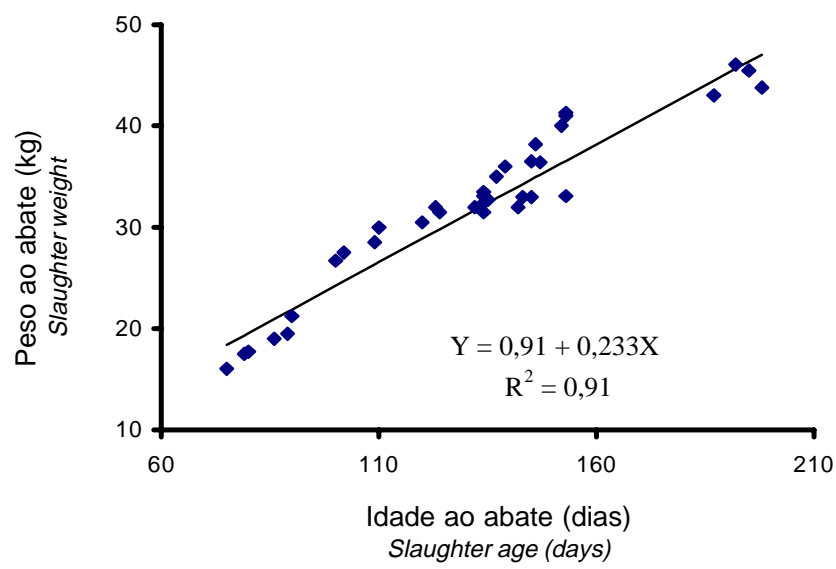

Figura 1 - Relação entre idade e peso de cordeiros Suffolk. Figure 1 - Relationship between age and weight of Suffolk lambs.

alimentados com dieta com elevada concentração energética e foram superiores aos de SIQUEIRA et al. (1998), para cordeiros Hampshire Down em confinamento, similares aos de MONTEIRO et al. (1998), para cordeiros mestiços Suffolk confinados, e inferiores aos de BUENO et al. (1998), para cordeiros Suffolk, em condições semelhantes ao deste estudo.

Os pesos do sangue, do couro, da cabeça, das patas, das vísceras, do conteúdo gastrintestinal, das vísceras vazias, do sistema digestivo vazio, do conjunto pulmão + traquéia + coração, dos rins, da gordura mesentérica, do fígado e da gordura perirenal apresentaram aumento linear com o aumento da idade de abate, devido ao incremento de peso vivo dos animais e, conseqüentemente, de seus componentes. Contudo, quando expressos como porcentagem do peso vivo ao abate, o sangue, a cabeça, as patas, as vísceras cheias e o conteúdo gastrintestinal mostraram diminuição linear; a pele, a gordura perirenal e a gordura mesentérica, aumento linear; e as vísceras vazias, o sistema digestivo vazio, o pulmão-traqueiacoração, os rins e o fígado não se modificaram com o aumento da idade de abate. Estudo realizado por FARIA et al. (1997) com cordeiros Corriedale criados em pastagem e abatidos entre 100 e 150 dias mostrou diminuição das porcentagens de cabeça, patas, coração-pulmão-traquéia, fígado e rins, aumento na porcentagem do couro e não-alteração na porcentagem de vísceras totais (cheias), com o aumento da idade de abate, o que discorda deste estudo. $\mathrm{O}$ aumento das porcentagens de gordura mesentérica 
Tabela 2 - Idades, pesos de abate e componentes não-carcaça de cordeiros Suffolk (média \pm desvio-padrão), equações de regressão e coeficientes de determinação $\left(R^{2}\right)$, de acordo com a idade de abate $(X)$

Table 2 - Age and weight at slaughter and non-carcass components of Suffolk lambs, (means \pm standard deviation), regression equation and coefficient of determination $\left(R^{2}\right)$ in function of the slaughter age $(X)$

\begin{tabular}{|c|c|c|c|c|c|}
\hline $\begin{array}{l}\text { Componentes do peso vivo } \\
\text { Live weight components }\end{array}$ & & $\begin{array}{c}\text { Idade (dias) } \\
\text { Age (days) }\end{array}$ & & $\begin{array}{l}\text { Regressão } \\
\text { Regression }\end{array}$ & $\mathrm{R}^{2}$ \\
\hline$(\mathrm{Y})$ & 90 & 130 & 170 & & \\
\hline $\begin{array}{l}\text { Idade média ao abate (dias) } \\
\text { Average age at slaughter (days) }\end{array}$ & $87,6 \pm 9,7$ & $133,3 \pm 11,42$ & $172,9 \pm 20,3$ & - & - \\
\hline $\begin{array}{l}\text { Peso vivo ao abate }(\mathrm{kg}) \\
\text { Live weight at slaughter }(\mathrm{kg})\end{array}$ & $20,2 \pm 4,3$ & $32,7 \pm 2,5$ & $40,9 \pm 4,4$ & $\mathrm{Y}=0,91+0,233 \mathrm{X}$ & $0,91 * *$ \\
\hline $\begin{array}{l}\text { Peso vivo vazio }(\mathrm{kg}) \\
\text { Empty live weight }(\mathrm{kg})\end{array}$ & $17,0 \pm 4,0$ & $27,4 \pm 2,2$ & $35,4 \pm 3,8$ & $Y=-1,07+0,211 X$ & $0,93 * *$ \\
\hline $\begin{array}{l}\text { Sangue }(\mathrm{kg}) \\
\text { Blood }(\mathrm{kg})\end{array}$ & $1,1 \pm 0,24$ & $1,6 \pm 0,17$ & $1,9 \pm 0,18$ & $\mathrm{Y}=0,48+0,0076 \mathrm{X}$ & $0,53 * *$ \\
\hline $\begin{array}{l}\text { Sangue }(\%)^{1} \\
\operatorname{Blood}(\%)\end{array}$ & $5,2 \pm 0,54$ & $4,7 \pm 0,35$ & $4,4 \pm 0,86$ & $Y=6,10-0,013 X$ & $0,30 * *$ \\
\hline $\begin{array}{l}\text { Pele }(\mathrm{kg}) \\
\text { Skin }(k g)\end{array}$ & $2,1 \pm 0,77$ & $3,8 \pm 0,48$ & $4,8 \pm 0,78$ & $Y=-0,53+0,032 X$ & $0,80 * *$ \\
\hline $\begin{array}{l}\text { Pele }(\%)^{1} \\
\text { Skin }(\%)\end{array}$ & $9,9 \pm 1,51$ & $11,6 \pm 1,01$ & $11,7 \pm 1,24$ & $Y=8,41+0,022 X$ & $0,27 * *$ \\
\hline $\begin{array}{l}\text { Cabeça }(\mathrm{kg}) \\
\text { Head }(\mathrm{kg})\end{array}$ & $1,3 \pm 0,22$ & $1,8 \pm 0,14$ & $2,1 \pm 0,2$ & $\mathrm{Y}=0,48+0,0095 \mathrm{X}$ & $0,84 * *$ \\
\hline $\begin{array}{l}\text { Cabeça }(\%)^{1} \\
\text { Head }(\%)\end{array}$ & $6,3 \pm 0,38$ & $5,5 \pm 0,26$ & $5,1 \pm 0,27$ & $Y=7,27-0,013 X$ & $0,65 * *$ \\
\hline $\begin{array}{l}\text { Patas }(\mathrm{kg}) \\
\text { Legs }(\mathrm{kg})\end{array}$ & $0,65 \pm 0,12$ & $0,87 \pm 0,09$ & $1,06 \pm 0,14$ & $\mathrm{Y}=0,23+0,0048 \mathrm{X}$ & $0,77 * *$ \\
\hline $\begin{array}{l}\text { Patas }(\%)^{1} \\
\text { Legs }(\%)\end{array}$ & $3,25 \pm 0,28$ & $2,65 \pm 0,21$ & $2,59 \pm 0,23$ & $Y=3,69-0,0069 X$ & $0,41 * *$ \\
\hline $\begin{array}{l}\text { Vísceras cheias }(\mathrm{kg}) \\
\text { Full viscera }(\mathrm{kg})\end{array}$ & $6,09 \pm 1,12$ & $9,78 \pm 0,92$ & $11,43 \pm 1,12$ & $Y=1,64+0,058 \mathrm{X}$ & $0,76 * *$ \\
\hline $\begin{array}{l}\text { Vísceras cheias }(\%)^{1} \\
\text { Full viscera }(\%)\end{array}$ & $30,35 \pm 2,38$ & $29,91 \pm 1,91$ & $28,07 \pm 2,28$ & $Y=33,86-0,033 X$ & $0,22 * *$ \\
\hline $\begin{array}{l}\text { Conteúdo gastrintestinal }(\mathrm{kg}) \\
\text { Gastrointestinal content }(\mathrm{kg})\end{array}$ & $3,22 \pm 0,56$ & $5,36 \pm 0,74$ & $5,51 \pm 0,95$ & $Y=1,98+0,022 X$ & $0,36 * *$ \\
\hline $\begin{array}{l}\text { Conteúdo gastrintestinal }(\%)^{1} \\
\text { Gastrointestinal content }(\%)\end{array}$ & $16,21 \pm 2,64$ & $16,37 \pm 1,97$ & $13,62 \pm 2,89$ & $Y=20,83-0,039 X$ & $0,24 * *$ \\
\hline $\begin{array}{l}\text { Vísceras vazias }(\mathrm{kg}) \\
\text { Empty viscera }(\mathrm{kg})\end{array}$ & $2,86 \pm 0,7$ & $4,42 \pm 0,4$ & $5,93 \pm 0,96$ & $Y=-0,33+0,036 X$ & $0,90 * *$ \\
\hline $\begin{array}{l}\text { Vísceras vazias }(\%)^{1} \\
\text { Empty viscera }(\%)\end{array}$ & $14,14 \pm 1,02$ & $13,53 \pm 0,85$ & $14,45 \pm 1,47$ & - & $0,04 \mathrm{~ns}$ \\
\hline $\begin{array}{l}\text { Sistema digestivo vazio }(\mathrm{kg}) \\
\text { Empty digestive tract }(\mathrm{kg})\end{array}$ & $1,96 \pm 0,45$ & $3,05 \pm 0,3$ & $4,03 \pm 0,58$ & $Y=-0,15+0,024 X$ & $0,90 * *$ \\
\hline $\begin{array}{l}\text { Sistema digestivo vazio }(\%)^{1} \\
\text { Empty digestive tract }(\%)\end{array}$ & $9,68 \pm 0,81$ & $9,32 \pm 0,68$ & $9,85 \pm 0,84$ & - & $0,02 \mathrm{~ns}$ \\
\hline $\begin{array}{l}\text { Pulmão-traquéia-coração (kg) } \\
\text { Lungs-trachea-heart (kg) }\end{array}$ & $0,54 \pm 018$ & $0,80 \pm 0,11$ & $1,13 \pm 0,45$ & $Y=-0,21+0,0077 X$ & $0,61 * *$ \\
\hline $\begin{array}{l}\text { Pulmão-traquéia-coração }(\%)^{1} \\
\text { Lungs-trachea-heart }(\%)\end{array}$ & $2,63 \pm 0,31$ & $2,44 \pm 0,31$ & $2,73 \pm 0,97$ & - & $0,05 \mathrm{~ns}$ \\
\hline $\begin{array}{l}\text { Rins }(\mathrm{g}) \\
\text { Kidney }(g)\end{array}$ & $81,3 \pm 32,3$ & $124,1 \pm 12,2$ & $144,9 \pm 20,2$ & $Y=21,2+0,71 X$ & $0,64 * *$ \\
\hline $\begin{array}{l}\text { Rins }(\%)^{1} \\
\text { Kidney }(\%)\end{array}$ & $0,372 \pm 0,061$ & $0,371 \pm 0,034$ & $0,35 \pm 0,041$ & 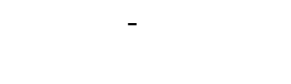 & $0,06 \mathrm{~ns}$ \\
\hline $\begin{array}{l}\text { Gordura mesentérica }(\mathrm{g}) \\
\text { Mesenteric fat }(\mathrm{g})\end{array}$ & $75,1 \pm 44,2$ & $214,1 \pm 100,1$ & $331,3 \pm 81,2$ & $Y=-193,1+3,2 X$ & $0,57 * *$ \\
\hline $\begin{array}{l}\text { Gordura mesentérica }(\%)^{1} \\
\text { Mesenteric fat }(\%)\end{array}$ & $0,27 \pm 0,18$ & $0,62 \pm 0,25$ & $0,81 \pm 0,20$ & $Y=-0,22+0,0061 X$ & $0,41 * *$ \\
\hline $\begin{array}{l}\text { Fígado (Liver), } \mathrm{g} \\
\text { Fígado (Liver), } \% 1\end{array}$ & $\begin{array}{c}372,1 \pm 91,1 \\
1,84 \pm 0,31\end{array}$ & $\begin{array}{l}581,2 \pm 61,1 \\
1,78 \pm 0,138\end{array}$ & $\begin{array}{l}762 \pm 112,0 \\
1,87 \pm 0,28\end{array}$ & $\mathrm{Y}=187,1+4,2 \mathrm{X}$ & $\begin{array}{l}0,75^{* *} \\
0,01 \mathrm{~ns}\end{array}$ \\
\hline Gordura perirenal (g) & $81,2 \pm 53,4$ & $181,1 \pm 51,2$ & $240,1 \pm 51,3$ & $Y=-6,66+1,8 X$ & $0,58 * *$ \\
\hline $\begin{array}{l}\text { Perirenal fat }(g) \\
\text { Gordura perirenal }(\%)^{1} \\
\text { Perirenal fat }(\%)\end{array}$ & $0,37 \pm 0,22$ & $0,55 \pm 0,14$ & $0,59 \pm 0,10$ & $Y=0,173+0,0026 \mathrm{X}$ & $0,24 * *$ \\
\hline
\end{tabular}

** $(\mathrm{P}<0,01),{ }^{n s}(\mathrm{P}>0,05) .{ }^{1}$ Porcentagem do peso vivo ao abate (Percentage of slaughter weight). 
Rev. bras. zootec.

e perirenal, com o aumento da idade dos animais, está de acordo com WOOD et al. (1980) e mostra-se indesejável do ponto de vista comercial.

$\mathrm{Na}$ Tabela 3 são apresentados o rendimento de carcaça, de seus cortes e seus componentes e as equações lineares que descrevem a relação entre a idade de abate, em dias, com estas variáveis. Pode-se observar que houve aumento linear do peso das carcaças quente e fria, de seus cortes e componentes, denotando o acréscimo de tecidos nas carcaças, devido ao aumento de peso vivo dos animais.

Os rendimentos quente, frio ou comercial e verdadeiro aumentaram linearmente com o aumento do idade de abate, devido à diminuição das porcentagens de alguns componentes não-carcaça: sangue, cabeça, patas, vísceras e conteúdo gastrintestinal. CARVALHO et al. (1980) e LLOYD et al. (1980) também observaram elevação do rendimento de carcaça com o aumento de peso de abate dos animais. Os rendimentos frios (comercial) encontrados neste estudo para os animais mais erados foram superiores aos encontrados por SANTOS et al. (1998), para cordeiros mestiços Suffolk abatidos ao redor de 150 dias de idade, e por CUNHA et al. (1998), para cordeiros mestiços Ile de France com esta mesma idade. O aumento do rendimento de carcaça em animais mais erados, apesar de favorável comercialmente, leva à produção de carcaças com maior teor de gordura, que é confirmado pela correlação positiva entre rendimento de carcaça fria e porcentagem de gordura na carcaça $(r=0,60)$, o que concorda com SOLOMON et al. (1980).

Os cortes da carcaça, quando expressos em porcentagem da carcaça fria, mostraram variações decorrentes do aumento da idade dos animais. Foi observado diminuição do traseiro, aumento do costilhar e não-alteração no dianteiro, mostrando que o aumento da idade de abate leva à diminuição da parte mais nobre da carcaça, o traseiro.

A separação física dos componentes (tecidos) das carcaças mostrou que o aumento da idade de abate de cordeiros Suffolk levou à diminuição linear da porcentagem de ossos e acréscimo de gordura, sem alterar a de músculos. Isso mostra que a elevação da maturidade dos animais, determinado pelo aumento de sua idade de abate, modifica a composição tecidual das carcaças, o que concorda inteiramente com TAYLOR (1985) e BASS et al. (1990). As porcentagens de músculo deste estudo foram similares, a de ossos, superiores e as de gordura, inferiores às encontradas por LATIF e OWENS (1980) para cordeiros mestiços Suffolk abatidos com $36 \mathrm{~kg}$. A porcentagem de gordura na carcaça, mesmo para os animais mais pesados, foram menores que as citadas por BASS et al. (1990) e WOOD et al. (1980).

A perda por oreio (Tabela 3) apresentou relação significativa inversa com a idade de abate dos animais e correlação negativa com o peso de carcaça fria $(r=-0,68)$, evidenciando que animais mais velhos apresentam menor perda de peso da carcaça fria por desidratação que os mais jovens. A cobertura de gordura das carcaças e seu estado de engraxamento exercem proteção contra as perdas por desidratação das carcaças frias (OSÓRIO et al., 1997), sendo evidenciado pelas correlações negativas entre esta variável e nota de cobertura de gordura $(r=-0,64)$, espessura da gordura subcutânea $(r=-0,55)$ e porcentagem de gordura na carcaça $(r=-0,53)$.

As medidas de carcaça, comprimento interno, profundidade torácica, comprimento e circunferência da perna e largura da garupa mostraram relação linear positiva com a idade de abate. A profundidade do tórax apresentou o melhor valor de coeficiente de determinação com a idade de abate $\left(\mathrm{R}^{2}=0,77\right) \mathrm{e}$, de forma semelhante ao comprimento interno, coeficientes de correlação com o peso de carcaça fria mais elevados $(r=0,88)$ que os das demais medidas de carcaça, os quais podem ser utilizados para estimar o peso de carcaça com maior precisão. EL KARIM et al. (1988) mostraram que a profundidade do tórax é a medida que melhor se correlaciona com o peso de carcaça. O comprimento interno da carcaça pode ser utilizado como indicador de características de carcaça, pois mostrou elevada correlação com a porcentagem de traseiro $(r=-0,80)$, porcentagem de costilhar $(\mathrm{r}=0,77)$, porcentagem de ossos $(\mathrm{r}=-0,73)$, peso dos ossos $(r=0,84)$, peso dos músculos $(r=0,89)$, porcentagem de gordura $(\mathrm{r}=0,70)$, peso da gordura $(r=0,79)$, espessura da gordura subcutânea $(r=0,72)$, compacidade $(r=0,81)$ e nota para cobertura de gordura $(r=0,81)$, o que concorda com WOOD et al. (1980), ao afirmarem que o comprimento interno da carcaça é bom indicador de peso e características de carcaças. A profundidade do tórax também se mostrou boa indicadora de características de carcaça, pois apresentou correlação com a porcentagem de traseiro $(r=-0,85)$, porcentagem de costilhar $(r=0,86)$, área de olho de lombo $(r=0,71)$, espessura da gordura subcutânea $(r=0,78)$, nota para a cobertura de gordura $(r=0,87)$, porcentagem de ossos $(r=-0,80)$, porcentagem de gordura $(r=0,76)$, peso de ossos $(r=0,79)$, peso de músculos $(r=0,89)$, peso de gordura $(r=0,81)$ e compacidade $(r=0,86)$. 
Tabela 3 - Rendimento de carcaça, de seus cortes e de seus componentes (média \pm desvio-padrão), equações de regressão e coeficientes de determinação $\left(R^{2}\right)$, de acordo com a idade de abate de cordeiros $(X)$

Table 3 - Carcass yield, cuts and components carcass yields (means \pm standard deviation), regression equations and coefficients of determination $\left(R^{2}\right)$, in function of the slaughter age of lambs $(X)$

\begin{tabular}{|c|c|c|c|c|c|}
\hline \multirow{2}{*}{$\begin{array}{l}\text { Componentes da carcaça } \\
\text { Carcass component } \\
\text { (Y) }\end{array}$} & \multicolumn{3}{|c|}{$\begin{array}{c}\text { Idade (dias) } \\
\text { Age (days) }\end{array}$} & \multirow[t]{2}{*}{$\begin{array}{l}\text { Regressão } \\
\text { Regression }\end{array}$} & \multirow[t]{2}{*}{$\mathrm{R}^{2}$} \\
\hline & 90 & 130 & 170 & & \\
\hline $\begin{array}{l}\text { Carcaça quente }(\mathrm{kg}) \\
\text { Warm carcass }(\mathrm{kg})\end{array}$ & $9,28 \pm 2,02$ & $15,07 \pm 1,27$ & $20,14 \pm 2,58$ & $Y=-1,41+0,124 x$ & $0,94 * *$ \\
\hline $\begin{array}{l}\text { Rendimento quente }(\%) \\
\text { Warm carcass yield }(\%)\end{array}$ & $44,92 \pm 1,48$ & $45,59 \pm 1,54$ & $48,16 \pm 1,9$ & $Y=40,67+0,041 x$ & $0,43 * *$ \\
\hline $\begin{array}{l}\text { Carcaça fria }(\mathrm{kg}) \\
\text { Cold carcass }(\mathrm{kg})\end{array}$ & $8,47 \pm 2,06$ & $14,09 \pm 1,30$ & $18,82 \pm 2,63$ & $Y=-1,76+0,119 x$ & $0,92 * *$ \\
\hline $\begin{array}{l}\text { Rendimento frio }(\%) \\
\text { Cold carcass yield }(\%)\end{array}$ & $41,76 \pm 1,91$ & $43,04 \pm 1,58$ & $45,92 \pm 1,87$ & $Y=36,66+0,051 x$ & $0,54 * *$ \\
\hline $\begin{array}{l}\text { Rendimento verdadeiro }(\%) \\
\text { True carcass yield }(\%)\end{array}$ & $49,83 \pm 1,28$ & $51,47 \pm 1,27$ & $53,16 \pm 0,97$ & $Y=46,67+0,036 x$ & $0,52 * *$ \\
\hline $\begin{array}{l}\text { Dianteiro }(\mathrm{kg})^{1} \\
\text { Forequarter }(\mathrm{kg})\end{array}$ & $1,67 \pm 0,45$ & $2,74 \pm 0,31$ & $3,59 \pm 0,49$ & $Y=-0,209+0,0220 X$ & $0,87 * *$ \\
\hline $\begin{array}{l}\text { Dianteiro }(\%)^{1} \\
\text { Forequarter }(\%)\end{array}$ & $38,88 \pm 1,30$ & $39,37 \pm 1,25$ & $38,75 \pm 1,05$ & - & $0,01 \mathrm{~ns}$ \\
\hline $\begin{array}{l}\text { Traseiro }(\mathrm{kg})^{1} \\
\text { Hindquarter }(\mathrm{kg})\end{array}$ & $2,18 \pm 0,52$ & $3,31 \pm 0,285$ & $4,32 \pm 0,57$ & $Y=0,064+0,024 X$ & $0,87 * *$ \\
\hline $\begin{array}{l}\text { Traseiro }(\%)^{1} \\
\text { Hindquanrter }(\%)\end{array}$ & $50,85 \pm 1,39$ & $47,63 \pm 1,20$ & $46,66 \pm 1,28$ & $Y=54,38-0,047 X$ & $0,60 * *$ \\
\hline $\begin{array}{l}\text { Costilhar }(\mathrm{kg})^{1} \\
\text { Ribs }(k g)\end{array}$ & $0,45 \pm 0,14$ & $0,91 \pm 0,11$ & $1,35 \pm 0,19$ & $Y=-0,42+0,010 X$ & $0,91 * *$ \\
\hline $\begin{array}{l}\text { Costilhar }(\%)^{1} \\
\text { Ribs }(\%)\end{array}$ & $10,27 \pm 0,79$ & $13,01 \pm 0,91$ & $14,59 \pm 1,03$ & $Y=6,74+0,046 \mathrm{X}$ & $0,70 * *$ \\
\hline $\begin{array}{l}\text { Osso total }(\mathrm{kg})^{1} \\
\text { Total bone }(\mathrm{kg})\end{array}$ & $1,20 \pm 0,24$ & $1,57 \pm 0,19$ & $1,80 \pm 0,16$ & $Y=0,63+0,0069 X$ & $0,62 * *$ \\
\hline $\begin{array}{l}\text { Osso total }(\%)^{1} \\
\text { Total bone }(\%)\end{array}$ & $29,57 \pm 3,47$ & $22,89 \pm 1,82$ & $19,71 \pm 1,35$ & $Y=36,38-0,099 X$ & $0,71 * *$ \\
\hline $\begin{array}{l}\text { Músculo total }(\mathrm{kg})^{1} \\
\text { Total muscle }(\mathrm{kg})\end{array}$ & $2,60 \pm 0,56$ & $4,23 \pm 0,378$ & $5,56 \pm 0,63$ & $Y=-0,22+0,0332 X$ & $0,91 * *$ \\
\hline $\begin{array}{l}\text { Músculo total }(\%)^{1} \\
\text { Total muscle }(\%)\end{array}$ & $61,32 \pm 3,12$ & $61,08 \pm 2,16$ & $60,47 \pm 2,88$ & - & $0,04 \mathrm{~ns}$ \\
\hline $\begin{array}{l}\text { Gordura total }(\mathrm{kg})^{1} \\
\text { Total fat }(\mathrm{kg})\end{array}$ & $0,47 \pm 0,36$ & $1,13 \pm 0,2501$ & $1,85 \pm 0,45$ & $Y=-0,94+0,016 X$ & $0,90 * *$ \\
\hline $\begin{array}{l}\text { Gordura total }(\%)^{1} \\
\text { Total fat }(\%)\end{array}$ & $10,11 \pm 4,72$ & $16,23 \pm 2,91$ & $19,82 \pm 2,81$ & $Y=0,69+0,1123 X$ & $0,60 * *$ \\
\hline $\begin{array}{l}\text { Perda por oreio }(\%) \\
\text { Cold storage losses }(\%)\end{array}$ & $7,6 \pm 1,0$ & $6,0 \pm 0,8$ & $4,9 \pm 0,5$ & $Y=10,29-0,032 X$ & $0,35 * *$ \\
\hline
\end{tabular}

${ }^{1}$ Na meia-carcaça fria, ${ }^{* *}-(P<0,01)$, ns- $(P>0,05)$.

1 In the half cold carcass.

A área de olho de lombo apresentou aumento linear positivo com a idade de abate (Tabela 4) e correlação positiva com o peso da carcaça fria $(\mathrm{r}=0,78)$. Isso mostra que o aumento do peso vivo do animal leva a incremento desta variável, a qual apresentou pequena correlação com a porcentagem de músculos da carcaça $(\mathrm{r}=-0,21)$, porém mostrou valor mais elevado de correlação com o peso dos músculos da carcaça $(r=0,79)$, mostrando que esta variável pode predizer a quantidade, e não a porcentagem de músculos na carcaça.

$\mathrm{Na}$ Tabela 4 observa-se que a espessura da gordura subcutânea mostrou aumento linear positivo com a idade de abate e denota que o aumento da maturidade dos animais levou a incremento desta variável, o que concorda com TAYLOR et al. (1985), e apresentou correlação positiva com o porcentagem de gordura da carcaça $(r=0,78)$, o peso de gordura na carcaça $(\mathrm{r}=0,84)$ e o peso de músculos na carcaça fria $(r=0,81)$ e correlação negativa com a porcentagem de ossos ( $r=-078)$, o que corrobora os achados de SAINS (1996) e denota sua utilidade para caracterizar carcaças.

A nota para a cobertura de gordura das carcaças mostrou acréscimo linear positivo com o aumento da idade de abate de cordeiros e correlação positiva 
Rev. bras. zootec.

Tabela 4 - Medidas de carcaça de cordeiros, pH, equações de regressão e coeficientes de determinação $\left(R^{2}\right)$, de acordo com idade de abate $(X)$

Table 4 - Lamb carcass measures, $\mathrm{pH}$, regression equations and coefficients of determination $\left(R^{2}\right)$ in function of the slaughter age $(X)$

\begin{tabular}{|c|c|c|c|c|c|}
\hline \multirow{2}{*}{$\begin{array}{l}\text { Medidas de carcaça } \\
\text { Carcass measures } \\
\text { (Y) }\end{array}$} & \multicolumn{3}{|c|}{$\begin{array}{l}\text { Idade (dias) } \\
\text { Age (days) }\end{array}$} & \multirow[t]{2}{*}{$\begin{array}{l}\text { Regressão } \\
\text { Regression }\end{array}$} & \multirow[t]{2}{*}{$\mathrm{R}^{2}$} \\
\hline & 90 & 130 & 170 & & \\
\hline $\begin{array}{l}\text { Nota cobertura de gordura } \\
\text { Fat covering grade }\end{array}$ & $0,50 \pm 0,43$ & $2,13 \pm 0,46$ & $2,81 \pm 0,75$ & $Y=-1,8+0,028 X$ & $0,76 * *$ \\
\hline $\begin{array}{l}\text { Olho de lombo }\left(\mathrm{cm}^{2}\right) \\
\text { Longissimus muscle area }\left(\mathrm{cm}^{2}\right)\end{array}$ & $9,2 \pm 1,64$ & $12,3 \pm 1,33$ & $14,8 \pm 1,96$ & $\mathrm{Y}=4,3+0,060 \mathrm{X}$ & $0,62 * *$ \\
\hline $\begin{array}{l}\text { Gordura subcutânea (mm) } \\
\text { Subcutaneous fat (mm) }\end{array}$ & $0,3 \pm 0,26$ & $1,4 \pm 0,68$ & $2,9 \pm 0,92$ & $Y=-2,0+0,026 X$ & $0,69 * *$ \\
\hline $\begin{array}{l}\text { Comprimento interno }(\mathrm{cm}) \\
\text { Internal length }(\mathrm{cm})\end{array}$ & $50,8 \pm 2,43$ & $57,9 \pm 2,04$ & $60,9 \pm 2,53$ & $\mathrm{Y}=42,4+0,111 \mathrm{X}$ & $0,71 * *$ \\
\hline $\begin{array}{l}\text { Profundidade tórax }(\mathrm{cm}) \\
\text { Thorax depth }(\mathrm{cm})\end{array}$ & $26,9 \pm 2,3$ & $32,2 \pm 1,27$ & $34,5 \pm 1,07$ & $Y=20,4+0,084 X$ & $0,77 * *$ \\
\hline $\begin{array}{l}\text { Comprimento da perna }(\mathrm{cm}) \\
\text { Leg length }(\mathrm{cm})\end{array}$ & $32,1 \pm 2,4$ & $36,1 \pm 2,2$ & $37,1 \pm 2,2$ & $Y=28,9+0,049 X$ & $0,30 * *$ \\
\hline $\begin{array}{l}\text { Largura da garupa }(\mathrm{cm}) \\
\text { Rump width }(\mathrm{cm})\end{array}$ & $15,6 \pm 0,74$ & $19,7 \pm 1,7$ & $21,3 \pm 1,8$ & $Y=11,1+0,060 X$ & $0,60 * *$ \\
\hline $\begin{array}{l}\text { Circunferência da perna }(\mathrm{cm}) \\
\text { Leg circumference }(\mathrm{cm})\end{array}$ & $32,9 \pm 2,8$ & $37,9 \pm 5,6$ & $42,1 \pm 1,5$ & $Y=25,4+0,093 X$ & $0,31^{*}$ \\
\hline $\begin{array}{l}\text { Compacidade }(\mathrm{kg} / \mathrm{cm}) \\
\text { Compactness }(\mathrm{kg} / \mathrm{cm})\end{array}$ & $0,17 \pm 0,04$ & $0,24 \pm 0,02$ & $0,31 \pm 0,04$ & $\mathrm{Y}=0,023+0,0017 \mathrm{X}$ & $0,90 * *$ \\
\hline $\mathrm{pH}_{0}$ & $6,67 \pm 0,17$ & $6,57 \pm 0,15$ & $6,48 \pm 0,12$ & $Y=6,86-0,00211 \mathrm{X}$ & $0,35^{*}$ \\
\hline $\mathrm{pH}_{48}$ & $5,94 \pm 0,09$ & $5,82 \pm 0,16$ & $5,78 \pm 0,17$ & $\mathrm{Y}=6,09-0,00194 \mathrm{X}$ & $0,32 * *$ \\
\hline
\end{tabular}

com o peso da carcaça fria $(r=0,90)$. Apresentou também correlações positivas com a espessura de gordura subcutânea $(r=0,86)$ e a porcentagem $(r=0,88)$ e quantidade de gordura na carcaça $(r=0,90)$, indicando que pode ser utilizada para caracterizar as carcaças quanto à sua deposição de gordura.

A compacidade das carcaças mostrou acréscimo linear positivo com a idade de abate e correlação positiva com o peso da carcaça fria $(r=0,99)$, denotando que o aumento da idade de abate e, conseqüentemente, do peso da carcaça leva à maior deposição de tecidos por unidade de comprimento. Esta variável mostrou correlação positiva com a porcentagem de gordura das carcaças $(\mathrm{r}=0,84)$ e negativa com a porcentagem de ossos $(r=-0,84)$, evidenciando que o aumento do peso de tecidos por unidade de comprimento decorreu de maior deposição de gordura. Os valores observados para os animais de idade intermediária foram semelhantes ao de BUENO et al. (1998) para cordeiros Suffolk confinados alimentados com diferentes volumosos.

Os valores de $\mathrm{pH}$ das carcaças no momento do abate $(\mathrm{pH} 0)$ e na carcaça fria ( $\mathrm{pH} 48)$ mostraram decréscimo linear com o aumento da idade de abate dos animais, denotando, provavelmente, maior reserva de glicogênio nos animais mais velhos. A queda dos valores de $\mathrm{pH}$ observados foram adequados para o processo de maturação das carcaças e similares aos de LEMOS NETO et al. (1998) para cordeiros mestiços terminados em confinamento.

\section{Conclusões}

A idade de abate de cordeiros Suffolk determina as proporções da maioria dos componentes não-carcaça, o rendimento e as características de carcaça, principalmente o seu teor de gordura e proporção de ossos.

O comprimento interno e a profundidade do tórax podem estimar o peso e algumas características de carcaças.

A nota para a cobertura de gordura é bom indicador de porcentagem de gordura das carcaças.

A idade de abate de cordeiros da raça Suffolk criados intensivamente para produzir carcaças com peso adequado ao consumidor da região Centro-Sul do Brasil situa-se entre 110 e 130 dias. Essas carcaças possuem boa proporção de músculos, teor moderado de gordura e cobertura de gordura adequada para amenizar sua desidratação na armazenagem a frio. 


\section{Agradecimento}

Aos funcionários de apoio à pesquisa científica $\mathrm{e}$ tecnológica Paulo Pereira dos Santos, Onofre Martins, José Sperch, José Aparecido de Oliveira, Pedro Joaquim da Silva e Olinda Aparecida de Oliveira Costa, pela valiosa colaboração na excecução deste trabalho.

\section{Referências Bibliografias}

BASS, J.J., BUTLER-HOGG, B.W., KITTON, A.H. 1990. Practical methods of controlling fatness in farm animals. In: WOOD, J.D., FISHER, A.V. (Ed.). Reducing fat in meat animals. London: Elsevier Science Publishers. p.145-200.

BUENO, M.S., CUNHA, E.A., SANTOS, L.E. et al. Desempenho e características de carcaça de cordeiros Suffolk alimentados com diferentes tipos de volumosos. In: REUNIÃO ANUAL DA SOCIEDADE BRASILEIRA DE ZOOTECNIA, 35, Botucatu, 1998. Anais... Botucatu: SBZ, 1998, v.1. p.206-208.

CARVALHO, J.B.P., PEDROSO, J.R., FIGUEIRÓ, P. et al. 1980. Alguns fatores que afetam o rendimento da carne ovina. Rev. Centro Ciências Rurais, 10(2):95-104.

CUNHA, E.A., SANTOS, L.E., BUENO, M.S. et al. Efeito do cruzamento de carneiros Ile de France, com ovelhas produtoras de lã, sobre a produção de carne. In: REUNIÃo ANUAL DA SOCIEDADE BRASILEIRA DE ZOOTECNIA, 35, Botucatu, 1998. Anais... Botucatu: SBZ, 1998, v.4. p.567-569.

EL KARIN, A.I.A., OWENS, J.B., WHITAKER, C.J. 1988. Measurement on slaughter weight, side weight, carcass joints and their association with composition of two types of sudan desert sheep. J. Agric. Sci., 110:65-69.

FARIA, V.F., OSÓRIO, J.C., ROQUE, A.P. et al. Avaliação do crescimento, morfologia e componentes do peso vivo em cordeiros Corriedale. In: REUNIÃO ANUAL DA SOCIEDADE BRASILEIRA DE ZOOTECNIA, 34, JUIZ DE FORA, 1997. Anais... Juiz de Fora: SBZ, 1997. p.269-271.

FISHER, A.V. 1990. New approaches to measuring fat in the carcasses of meat animals. In: WOOD, J.D., FISHER, A.V. (Eds.) Reducing fat in meat animals. London: Elsevier Science Publishers. p.255-343.

LATIF, M.G.A., OWENS, E. 1980. A note on the growth performance and carcass composition of texel and suffolk sire lambs in an intensive feeding system. Anim. Prod., 30:311-314.

LEMOS NETO, M.J., SIQUEIRA, E.R., FERNANDES, S. et al. Caracteres qualitativos da carne de cordeiros corriedale e ile de France x Corriedale terminados em confinamento. In: REUNIÃO ANUAL DA SOCIEDADE BRASILEIRA DE ZOOTECNIA, 35, Botucatu, 1998. Anais... Botucatu: SBZ, 1998, v.4. p.701-703.

LLOYD, W.R., SLYTER, A.L., COSTELLO, W.J. 1980. Eftfect of breed, sex and final weight on feedlot performance, carcass characteristic and meat palatability of lambs. J. Anim. Sci., 51(2):316-320.
MONTEIRO, A.L.G., GARCIA, C.A., NERES, M.A. et al. Efeito da substituição do milho pela polpa cítrica no desempenho e características das carcaças de cordeiros confinados. In: REUNIÃO ANUAL DA SOCIEDADE BRASILEIRA DE ZOOTECNIA, 35, Botucatu, 1998. Anais... Botucatu: SBZ, 1998, v.1. p.95-97.

OSÓRIO, M.T., SIERRA, I., SAÑUDO, C. et al. Peso vivo ao abate, da carcaça e perdas por oreio, segundo raça, sexo e idade em cordeiros. In: REUNIÃO ANUAL DA SOCIEDADE BRASILEIRA DE ZOOTECNIA, 34, Juiz de Fora, 1997. Anais... Juiz de Fora: SBZ, 1997. p.299-301.

SAINS, R.D. Qualidade de carcaças e da carne de ovinos e caprinos. In: REUNIÃO ANUAL DA SOCIEDADE BRASILEIRA DE ZOOTECNIA/SIMPÓSIO INTERNACIONAL SOBRE TÓPICOS ESPECIAIS EM ZOOTECNIA, 33, Fortaleza, 1996. Anais... Fortaleza: SBZ, 1996. p.3-14.

SANTOS, L.E., CUNHA, E.A., BUENO, M.S. et al. Efeito do cruzamento de carneiros Suffolk, com ovelhas produtoras de lã, sobre a produção de carne. In: REUNIÃO ANUAL DA SOCIEDADE BRASILEIRA DE ZOOTECNIA, 35, v.4, Botucatu, 1998. Anais... Botucatu: SBZ, 1998. p.570-572.

SIQUEIRA, E.R. Confinamento de ovinos. In: SIMPÓSIO PAULISTA DE OVINOCULTURA E ENCONTRO INTERNACIONAL DE OVINOCULTURA, 5, Botucatu, 1999. Anais... Botucatu:UNESP, CATI, IZ, ASPACO, 1999. p.52-59.

SIQUEIRA, E.R., FERNANDES, S., MESQUITA, V.S., et al.. Efeito do peso de abate sobre a eficiência de produção de cordeiros da raça Hampshire Down terminados em confinamento. In: REUNIÃO ANUAL DA SOCIEDADE BRASILEIRA DE ZOOTECNIA, 35, v. 4, Botucatu, 1998. Anais... Botucatu: SBZ, 1998. p.704-705.

SOLOMON, M.B., KEMP, J.D., MOODY, W.G. et al. 1980. Effect of breed and slaughter weight on phisical, chemical and organoleptic properties of lamb carcasses. J. Anim. Sci., 51(5):1103-1107.

TAYLOR, C.S. 1985. Use of genetic size scaling in evaluation of animal growth. J. Anim. Sci., 61(suppl.2):119-141.

WOOD, J.D., MACFIE, H.J.H., POMERY, R.W. et al. 1980. Carcass composition in four sheep breeds: The importance of breed and stage of maturity. Anim. Prod., 30:135-152.

WOOD, J.D., MACFIE, H.J.H. 1980. The significance of breed in the prediction of lamb carcass composition from fat thickness measurements. Anim. Prod., 31:315-319.

Recebido em: 19/01/99

Aceito em: 29/05/00 